\title{
REFLEXÕES SOBRE O DIÁLOGO SOCIAL NO PROCESSO DE IMPLANTAÇÃO DO CAMPUS IFRJ-NITERÓI
}

\section{REFLECTIONS ON SOCIAL DIALOGUE IN THE IFRJ-NITERÓI CAMPUS IMPLEMENTATION PROCESS}

Ligia Scarpa Bensadon ${ }^{74}$

\section{Resumo}

Este artigo parte da experiência no trabalho do IFRJ campus Niterói, em seu processo de implantação, trazendo à tona a reflexão sobre a importância da participação para a construção de uma instituição federal de educação, bem como na definição da sua identidade. Partimos dos dados obtidos em três pesquisas realizadas, contrastando com autores e fontes que abordam o tema da educação participativa. Foi observado aprofundamento no processo de diálogo social para o processo de implantação do campus, utilizando-se de diversos meios de comunicação e consulta com a sociedade, mas que, de outro lado, limitaram-se a um processo pontual no levantamento de demandas para a escolha de cursos na instituição.

Palavras-chave: Diálogo social. Participação. Institutos Federais.

\begin{abstract}
This article starts from the experience in the work of the IFRJ campus Niterói, in its implementation process, bringing up the reflection on the importance of participation for the construction of a federal educational institution, as well as in the definition of its identity. We start from the data obtained in three surveys carried out, contrasting with authors and sources that address the theme of participatory education. It was observed a deepening in the social dialogue process for the campus implantation process, using different means of communication and consultation with society, but, on the other hand, it was limited to a specific process in raising demands for the choice of courses at the institution.
\end{abstract}

Keywords: Social dialogue. Participation. Federal Institutes.

\footnotetext{
${ }^{74}$ Mestre em Ciências Sociais pela Universidade Federal Rural do Rio de Janeiro (UFRRJ). Professora do campus Niterói do Instituto Federal de Educação, Ciência e Tecnologia (IFRJ. Áreas de pesquisa: gestão, economia solidária, agroecologia, consumo responsável, sustentabilidade, território, redes e movimentos sociais. Contato: ligia.bensadon@ifrj.edu.br. ORCID: https://orcid.org/0000-0002-6202-6033
} 


\section{RevistAleph}

\section{Introdução}

Historicamente a educação é colocada como pauta importante para o desenvolvimento da sociedade brasileira, com a necessidade de investimento no setor de forma a efetivar o direito à educação de qualidade, a exemplo das orientações e diretrizes colocadas no Plano Nacional de Educação, na Constituição Federal de 1988 e na Lei de Diretrizes Bases da Educação (LDB) de 1996. Ainda hoje permanecemos com o desafio de a educação ser tratada como projeto de nação e política pública de longo prazo.

Na história da educação brasileira, é apenas a partir da década de 1930 que se pretendeu uma educação que pudesse abarcar o conjunto da população, com a criação de escolas primárias nos estados. Até então, a escola era um privilégio das elites e daqueles que podiam estudar no exterior ou ter acesso às escolas privadas ou públicas esparsas pelo país. Ainda assim, esse início de massificação passou por diversos avanços e recuos, sem que suas intenções se materializassem efetivamente na vida social ou, quando muito, numa educação que separava a proposta tecnicista para os trabalhadores e deixava a parte intelectual e diretiva para as elites, a exemplo das políticas encampadas no período da ditadura civil-militar.

Ainda atual é o Manifesto dos Pioneiros da Educação Nova de 1932, escrito por vários educadores e artistas no período republicano, contexto da então nascente sociedade industrial brasileira. No documento, esperava-se que a educação pudesse promover um processo de reconstrução nacional para um novo estágio socioeconômico de igualdade e consciência social. Isso se daria respondendo aos interesses, necessidades e protagonismo dos educandos e das comunidades. Contra uma educação considerada como artificial, desintegrada, passiva e verbalista da época, apontava-se a necessidade de uma política nacional de educação, na defesa de uma educação como direito, laica e democrática, sob responsabilidade do Estado. Neste documento, defendeu-se uma educação articulada aos aspectos técnicos, científicos e filosóficos, bem como das instituições escolares com outras esferas da vida social. 


\section{RevistAleph}

Fruto das pressões dos movimentos sociais, intelectuais e artistas, pelo menos desde o Manifesto, em 2008 foi criada a Rede Federal de Educação Profissional, Científica e Tecnológica, gerando a expansão dos Institutos Federais (IFs) pelo país, a partir da Lei 11.892/2008. Essa lei reitera a importância da educação como instrumento de garantia de direitos e de melhoria das condições de vida da população, tendo como finalidade formar e qualificar cidadãos nos diversos setores da economia, com ênfase no desenvolvimento socioeconômico local, regional e nacional, atendendo as demandas sociais e suas peculiaridades. Outro aspecto fundamental dos IFs é sua concepção de educação que articula trabalho, produção de conhecimento, artes, cultura e cidadania, no desafio da formação integral e crítica, bem como do currículo integrado, em especial para a classe-que-vive-do-trabalho (ANTUNES, 2015).

A partir de 2008, a Rede Federal expandiu-se pelo país, nas capitais e interiores, totalizando mais de 640 campi no período recente. A criação de cada um desses campi passa por um rito político e burocrático, desde a demanda municipal pela criação de um Instituto Federal (IF), até seu aceite pelo MEC e os processos de definição da sede junto da respectiva prefeitura municipal, contratação de funcionários e infraestrutura, entre tantos outros, até que uma nova instituição tenha mínimas condições de funcionar.

Esse processo não foi diferente para o campus Niterói do Instituto Federal de Educação, Ciência e Tecnologia do Rio de Janeiro (IFRJ), cuja experiência de implantação é o foco do presente artigo. Nosso recorte se coloca na análise sobre o processo de consulta e diálogo social empreendido pelo campus Niterói, entre novembro de 2016 e junho de 2017, o qual contou com a nossa participação, a fim de qualificar a escolha de novos e futuros cursos, ancorada nas demandas sociais e na realidade territorial.

As questões que trazemos objeto de reflexão são: De que forma um novo IF pode se estabelecer de modo coerente com seus propósitos político pedagógicos? Como a participação social pode contribuir para o processo de implantação de um novo Instituto Federal?

Frente a estas perguntas, o texto estrutura-se em quatro partes, além desta introdução. Iniciamos com uma breve apresentação do campus IFRJ - Niterói, seguido pela abordagem sobre a importância da participação social na definição da identidade 


\section{RevistAleph}

institucional. Na terceira parte apresentamos como foram realizados os diálogos sociais para as definições dos cursos do campus e, por fim, reflexões finais tecendo alguns fios do processo realizado, à luz dos seus propósitos e resultados.

Para a produção desse artigo foram utilizados documentos produzidos no âmbito do trabalho no IFRJ campus Niterói, em especial pela Comissão de pesquisa do perfil da cidade de Niterói para criação de cursos do campus, sob presidência da presente autora, como o relatório final do Plano de Implementação do Campus (PIC) (IFRJ, 2017). Assim, para a confecção desta pesquisa a metodologia utilizada focou-se nas experiências profissionais da autora, por meio de dados quantitativos, a partir dos levantamentos via formulários aplicados de forma online e presencial, além de dados qualitativos, a partir de reuniões com grupos de trabalho e convidados, numa abordagem exploratória dos temas refletidos, em diálogo com autores nos temas da educação, educação participativa e educação popular.

\section{Breve apresentação do campus IFRJ - Niterói e do município}

Atualmente, o IFRJ é constituído pelo campus Reitoria e por mais 15 campi espalhados pela região centro-sul fluminense. Dentre esses, o campus Niterói, integrante da Fase III do Plano de Expansão da Rede de Educação Profissional, Científica e Tecnológica, foi anunciado em 2011, mas teve suas atividades efetivamente iniciadas apenas em julho de 2016, após a contratação de servidores e da organização de espaço físico junto à prefeitura.

Os primeiros cursos ofertados foram na modalidade de Formação Inicial e Continuada de Trabalhadores (FIC) na área de serviços (Assistente Administrativo em Organização e Métodos, Operador de computador, Desenvolvimento de aplicativos, Espanhol e Inglês). Em 2017, foram abertas as primeiras turmas do Ensino Médio Técnico em Administração, na forma articulada concomitante e subsequente. E em 2019 na modalidade integrada ao ensino médio na área de Administração e Informática, já na sede definitiva do campus, no bairro do Sapê, em Niterói. Em 2020 foram iniciados os cursos de pós-graduação, com três especializações (Educação e novas tecnologias, 


\section{RevistAleph}

Gestão de Serviços e Gestão de Projetos Ambientais), contando com um corpo de mais de 40 servidores/as públicos/as.

A região onde o campus se localiza é caracterizada por baixos índices socioeconômicos do município, com concentração de moradias e baixas taxas de emprego, meio de locomoção e escolaridade, havendo a expectativa de que o campus altere a realidade local. Isso contrasta com a realidade do município, caracterizado por alto IDH, mas que expressa, semelhante ao restante do país, uma grande desigualdade social. Outra característica do município que orientou o processo de implantação do campus refere-se ao mercado de trabalho, com uma concentração de postos de trabalho na área de serviços, em especial nos setores educacionais e de saúde.

Compondo a região metropolitana do Rio de Janeiro, Niterói se destaca também pela pendularidade de pessoas entre seus municípios próximos, em especial São Gonçalo e Rio de Janeiro. E ainda, possui uma grande diversidade de ambientes naturais, como florestas, manguezais, campos inundáveis e restingas, que estão sob pressão do crescimento urbano e da especulação imobiliária.

\section{A participação social no processo de definição da identidade educacional}

Na construção do novo campus Niterói a questão que se colocou inicialmente para sua implantação foram decisões a respeito de quais atividades educacionais seriam oferecidas e quais seriam as suas justificativas. Isso porque, não raro, ocorre a definição de cursos e atividades em unidades educacionais limitadas aos interesses de seus docentes e/ou diretores, seja pelas suas áreas de atuação, seja pela facilidade na oferta de determinados cursos, o que não necessariamente estabelece um diálogo e análise sobre a pertinência e interesse social nestas ofertas educacionais. Tais escolhas podem gerar, num futuro não muito distante, cursos com baixa demanda, o fechamento dos mesmos e instituições que não são reconhecidas e identificadas por sua comunidade local. 


\section{RevistAleph}

Frente a essas e outras questões, um dos temas que permeia o processo de construção do IFRJ é justamente a sua identidade. No caso do IFRJ sua construção partiu desde 1998 das condições do antigo Centro Federal de Educação Profissional e Tecnológica de Química de Nilópolis (CEFETEQ), buscando articular o ensino da Educação Básica com o Ensino Superior em diversos novos campos do saber, repensando também as concepções produtivistas da escola, conforme a proposta originária dos Institutos Federais. A base cognitiva e material desde a área da química e da indústria não apenas foi o nascedouro para uma nova instituição, mas permeia também sua estrutura de poder. Exemplo disso é que todos os reitores do IFRJ foram oriundos da área da química, o que se espelha também na permanência de questões de raça e gênero, visto que todos esses reitores seguem o perfil de serem homens brancos.

Assim, pensar em identidade educacional requer considerar seus condicionantes históricos e estruturais, mas também perceber as mudanças ao longo dessa construção identitária, suas variações no tempo e no espaço em cada contexto social. Isso porque "a situação na qual o trabalho educativo se processa, os avanços e recuos, os problemas que os educadores enfrentam são produtos de construções históricas" (SAVIANI, 2008, p. 152), sendo possível agir sobre tais problemas e mudarIhes os rumos.

Sem pretender um detalhamento desse processo, a expansão do IFRJ foi relativamente rápida e descentralizada a partir de 2008, iniciando cursos até então estranhos ao que a instituição se consagrava, como na área da saúde (campus Realengo), produção cultural (campus Nilópolis) e turismo (campus Resende), por exemplo. A entrada nessas novas áreas corresponde também às mudanças no mundo do trabalho, com dinâmicas mais voltadas ao setor de serviços.

Essa ampliação gerou impactos na formação e transformação dessa identidade institucional e aproxima-se do cenário geral de deslocamentos e relocalizações dos pertencimentos e identidades culturais, configurando-se em novas heterogeneidades sociais (TEDESCO, 2001). Ou seja, a instituição que se limitava principalmente à área 


\section{RevistAleph}

industrial, passou a ampliar seu corpo de servidores e suas áreas de atuação temáticas e territoriais no estado do Rio de Janeiro.

De forma mais geral, acrescenta-se também o fato de que o poder de influência da instituição escolar na coesão social e na socialização dos estudantes se enfraqueceu, frente às mudanças sociais com o crescente uso de novos meios de comunicação, acesso à informação e interação pelo uso do celular, computador e seus aplicativos. Isso impacta também na própria definição da escola e no seu papel social. Ou seja, o desafio de manter a significação social das experiências de aprendizagem promovidas pela escola permanece, frente a tantos atrativos de informações fáceis e velozes, mas nem sempre confiáveis e educativas.

Tal situação configura, seguindo Tedesco (2001), uma crise de identidade social e de ausência de continuidade histórica ou de falta de sentido da época atual. Isso porque não há mais certezas, mas dúvidas e inseguranças num contexto de crescente precarização do trabalho e das expectativas de vida. As pessoas buscam não serem novamente excluídas: "nossas sociedades fingem que a urgência dos problemas as impede de refletir sobre um projeto, enquanto, na realidade, é a ausência total de perspectiva o que as faz escravas da urgência" (TEDESCO, 2001 apud LAÏDI, 1994).

O reforço ao valor do que seja público e do protagonismo dos indivíduos tornase mais imperativo nesse contexto, dado também o enfraquecimento das instituições primárias de socialização dos indivíduos, como a família. Isso pode gerar ou acentuar a personificação das instituições, fazendo política meramente com a subjetividade e o pessoal como referências, numa sociedade historicamente já marcada pela privatização e o clientelismo do que seja visto como público.

Essa falta de sentido e enfraquecimento de pertencimentos sociais pode gerar algumas consequências, como um retorno à pressão por seguir o critério econômico estritamente, o qual, por outro lado, não fornece nenhuma segurança às pessoas e acentua práticas competitivas e individualistas. Essa lacuna também pode ser preenchida por alternativas tortuosas, como um resgate às rígidas identidades do 


\section{RevistAleph}

passado como forma de proteção, a exemplo do retorno de pautas conservadoras, misóginas e autoritárias, como os pedidos de intervenção militar no período atual, ou então, a sensação de imobilismo e desconfiança frente a qualquer ideia de transformação e justiça social. Como aprendizado dessa situação, Tedesco (2001) nos traz a percepção da importância de que as identidades devem ser construídas, com um maior protagonismo dos indivíduos, recolocando o papel da escola para a construção de valores de tolerância e solidariedade num contexto de crise. Elaboração essa que não se faz isoladamente, mas em consonância e diálogo com a sociedade e a comunidade escolar local, o que reforça o papel da escola como espaço de aprendizado sobre a participação.

Conforme colocado anteriormente, a Lei 11.892/2008 estipula que os IFs devem atender às demandas locais, o que, consequentemente, passa pela compreensão e o diálogo sobre as demandas da e com a sociedade. Esse diálogo das organizações educacionais com a sociedade é também um requisito legal que, no caso do IFRJ, tem em seu regimento geral a presença da sociedade civil na composição do Conselho Superior, órgão máximo da instituição. Além disso, as atribuições dos Institutos incluem organizar o ensino, a pesquisa e a extensão de forma a atender as necessidades da sociedade, com o exercício democrático nas relações com a comunidade escolar, conforme o regulamento da educação profissional técnica de nível médio e do ensino médio do IFRJ. Essa gestão escolar democrática envolve o efetivo diálogo com a sociedade e suas organizações sociais, inclusive para atingir um amplo público que ainda está excluído da educação ofertada pela esfera federal.

As históricas lutas pela democratização da educação pública e de qualidade se inseriram na Constituição Federal de 1988 (inciso VI do art. 206) e na LDB (inciso VIII do art. 3) tanto pela participação dos profissionais da educação, quanto da comunidade escolar e local em instâncias como os conselhos escolares ou equivalentes, sendo isso assegurado também nos regimentos escolares. Essa participação objetiva pode permitir o protagonismo dos estudantes e de suas famílias, conforme colocado nas Diretrizes Curriculares Nacionais da Educação Básica, 


\title{
RevistAleph
}

Criando oportunidades institucionais para que todos os segmentos majoritários da população, que encontram grande dificuldade de se fazerem ouvir e de fazerem valer seus direitos, possam manifestar os seus anseios e expectativas e possam ser levados em conta, tendo como referência a oferta de um ensino com qualidade para todos (BRASIL, 2013, p. 174).

Nesse sentido, a identidade organizacional de uma instituição escolar define-se em consonância com as expectativas sociais, não sendo, portanto, algo externo ao conjunto da sociedade ou mesmo rígido e imutável, mas resultado dessa mútua interação. Isso deve incluir também aspectos específicos, como

\begin{abstract}
O processo de organização das turmas de estudantes, a distribuição de turmas por professor, as decisões sobre o currículo, a escolha dos livros didáticos, a ocupação do espaço, a definição dos horários e outras tarefas administrativas e/ou pedagógicas precisam priorizar o atendimento dos interesses e necessidades dos estudantes, e a gestão democrática é um dos fatores decisivos para assegurar a todos eles o direito ao conhecimento (BRASIL, 2013, p. 173).
\end{abstract}

O projeto político pedagógico das instituições escolares, documento que consolida a proposta de educação, partindo da visualização do seu contexto, desafios, objetivos, responsabilidades e estratégias, também requer essa construção coletiva, em especial com a comunidade escolar, que se insere num processo contínuo de avaliação que permita corrigir os rumos e incentivar as boas práticas (BRASIL, 2013).

Aprofundando o sentido e o horizonte da participação, a construção democrática pode ser percebida como a capacidade de escolha frente a opções diferentes para a resolução de um problema, ou seja, pressupõe compreensão e envolvimento com as questões. Essa participação pode expressar-se de formas diversas, diretas ou indiretas e, sendo autêntica, supõe ter algum tipo de exercício e mecanismo de poder, no sentido de direcionar o comportamento de algo.

É importante ressaltar que a participação pode se revestir de formas conflitivas, funcionais, administrativas e, inclusive, manipuladas, mas, de outro lado, há um formato mais profundo, a autogestão, que difere da participação porque não significa participar 


\title{
RevistAleph
}

de um poder, mas de ter efetivamente um poder (MOTTA, 1984). Tal horizonte complexifica o sentido dessa construção e pode ser visualizada no âmbito escolar em dois sentidos: a autogestão pedagógica, como dinâmica de trabalho educativo com estudantes, dentro da sala de aula, e a autogestão institucional relativa a administração do estabelecimento de ensino (MOTTA, 1984).

Uma escola que busque a formação cidadã requer então que se promova a participação e a tolerância em todos os seus espaços. Sem isso, a população não se perceberá como responsável pela sua própria educação e das suas instituições e, consequentemente, do seu próprio futuro como nação. Acrescenta-se o desafio das instituições escolares ensinarem também o próprio processo de escolha, com a necessidade de uma pedagogia diferente do modelo tradicional hierárquico. O exercício do trabalho em equipe, a solidariedade entre os indivíduos e a capacidade de escuta são elementos a serem trabalhados na teoria e na prática escolar em todos os seus âmbitos.

\begin{abstract}
A confiança em si mesmo constitui, desse ponto de vista, o fundamento inicial de qualquer estratégia de integração e compreensão do "outro". O medo, a insegurança, a subvalorização de si não podem, em nenhum caso, ser a fonte de uma nova cultura cidadã (TEDESCO, 2001, p. 81).
\end{abstract}

Corroborando com essa perspectiva, Motta (1984) indica que a construção de uma sociedade autogestionária passa pela educação politécnica e polivalente, em uma aprendizagem não autoritária que "impede a internalização dos mecanismos de submissão e conformidade" (MOTTA, 1984, p. 5), erradicando a dependência. Essa educação precisa fomentar o apoio mútuo e a ação direta, de forma a permitir um pensamento com autonomia, a amar e ser amado, e de uma cultura articulada com a vida.

Um dos requisitos, então, à participação no ambiente escolar é a capacidade de escuta e de diálogo, não como mero detalhe, mas como aspecto fundante e estruturante da gestão escolar: 


\section{RevistAleph}

[...] deveríamos entender o diálogo não como técnica apenas que podemos usar para conseguir obter resultados, ao contrário, o diálogo deve ser entendido como algo que faz parte da própria natureza histórica dos seres humanos. É parte de nosso movimento histórico do caminhar para nos tornarmos humanos (FREIRE; SHOR, 1987, p. 122).

E acrescentam:

[...] o diálogo é uma espécie de postura necessária, na medida em que os seres humanos se transformam cada vez mais em seres criticamente comunicativos. O diálogo é o momento em que os humanos se encontram para refletir sobre sua realidade tal como a fazem e refazem... Através do diálogo, refletindo juntos sobre o que sabemos, podemos, a seguir, atuar criticamente para transformar a realidade. [...] $O$ diálogo sela o relacionamento entre sujeitos cognitivos; podemos, a seguir, atuar criticamente para transformar a realidade... Eu acrescentaria que o diálogo valida ou invalida as relações sociais das pessoas envolvidas nessa comunicação... $O$ diálogo libertador é uma comunicação democrática, que invalida a dominação [...] ao afirmar a liberdade dos participantes de refazer a cultura [...] O diálogo implica responsabilidade, direcionamento, determinação, disciplina, objetivos [...] Significa uma tensão permanente entre a liberdade e autoridade (FREIRE; SHOR, 1987, p. 123).

Compreender a profundidade do significado do diálogo e da participação, como colocados pelos autores Freire e Shor (1987) e Motta (1984), traz sinalizações para a caminhada e nos faz retomar o olhar sobre o processo de implantação do campus IFRJ Niterói. O estabelecimento de uma nova organização educacional traz em si a possibilidade de ousar novas experiências, de uma construção que não requer manterse na reprodução do sistema existente, status quo, podendo então repensar e atuar sobre suas lacunas. O porvir traz sempre uma esperança. Nesse sentido, o novo retoma a necessidade de entender o presente e o passado, levantar os anseios sociais e refletir sobre a função social de uma nova instituição, partindo da base objetiva e subjetiva do que já foi trilhado.

Assim, a partir de um diálogo interno pelo whatsapp entre os servidores do campus em 2016, provocado pela presente autora, iniciou-se a proposição de uma consulta social que pudesse efetivamente ouvir e contar com a participação da comunidade. Foi então formada uma comissão de Pesquisa do Perfil da Cidade de 


\section{RevistAleph}

Niterói para criação dos Cursos do Campus, que atuou entre novembro de 2016 e junho de 2017.

\section{O diálogo e a consulta social realizados para a orientação das ofertas} educacionais do campus Niterói

Trazemos para análise o Plano de Implementação do Campus Niterói (PIC) realizado a partir de consultas à população para definir os eixos tecnológicos que norteariam as escolhas dos cursos a serem ofertados. Esse processo congregou três levantamentos realizados entre 2015 e 2017, por diferentes equipes.

O primeiro levantamento realizado, em setembro de 2015 , foi coordenado pelo primeiro diretor do campus e ocorreu junto de estudantes do 9 o ano de 5 escolas situadas no entorno do campus em construção, no bairro do Sapê, em Niterói. A análise dos 286 formulários respondidos apontou que os cursos técnicos mais demandados seriam de: Administração (17,3\%), Informática (13,3\%), Petróleo e Gás (7,5\%) e Enfermagem (7,3\%). Essa pesquisa indicou, ainda, a preferência por cursos diurnos (65\%) e integrados (64\%), apontando, também, como principal forma de acesso, o transporte público municipal (53\%) e a locomoção a pé (25\%). Apareceu, também, a demanda por cursos de curta duração, em áreas como inglês, técnico eletricista e artesanato, de preferência no horário noturno.

Nesse levantamento, mais focado no público local do entorno do campus, não houve a informação sobre o perfil desses jovens respondentes, estudantes do final do ensino fundamental, por exemplo, sobre moradia, renda, situação familiar, entre outros, que auxiliariam a compreender as possíveis motivações e realidade sobre seus interesses e necessidades.

A segunda pesquisa ocorreu em dezembro de 2016 , realizada com as primeiras turmas dos cursos de Formação Inicial e Continuada (FIC) do campus. Essa pesquisa 


\section{RevistAleph}

aproveitou a avaliação sobre os cursos concluídos e pediu que os respondentes apontassem suas expectativas quanto à oferta de novos cursos. Responderam ao questionário 52 estudantes, sendo 18 do curso FIC de Assistente Administrativo, 5 do curso de Operador de Computador, 13 do curso de Desenvolvimento de Aplicativos, 12 do curso de Inglês e 4 do de Espanhol. Os alunos indicaram diversos cursos nas áreas dos eixos tecnológicos disponíveis (era possível escolher mais de um curso por eixo). Foram citados com mais ênfase os cursos técnicos de Informática (32), Administração (29), Recursos Humanos (29), Produção de Áudio e Vídeo (24), Edificações (24), Serviços Jurídicos (21), Rede de Computadores (21) e Meio Ambiente (20). Verificou-se, assim, a preferência por cursos relacionados às áreas administrativas e de informática, seguido pelo interesse na área cultural e da construção civil.

Novamente aqui não se teve informação sobre o perfil dos respondentes, ainda que já fossem estudantes do campus, obtendo também mais conhecimento sobre a instituição. Ambas pesquisas iniciais limitaram-se a um levantamento quantitativo e pontual dos interesses em áreas de oferta de cursos, já previamente elencados nas opções disponíveis, sem efetivar um diálogo mais profundo sobre as expectativas junto ao campus e sobre como poderia ser sua atuação no ensino, na pesquisa e na extensão. De toda a forma, ambas as primeiras pesquisas reforçaram cursos nas mesmas áreas, a saber, informática e administração, consoante também às necessidades gerais para o mundo do trabalho.

Por fim, a terceira pesquisa ocorreu entre março e maio de 2017 , e conjugou uma ampla consulta pública para aprofundar o levantamento sobre os interesses educacionais da população junto ao novo campus do IFRJ. Essa última pesquisa foi realizada pela Comissão de pesquisa do perfil da cidade de Niterói para criação dos cursos, apresentada anteriormente, e realizou um plano de trabalho com atividades de levantamento socioeconômico sobre a região, utilizando fontes diversas, como: IBGE (Instituto Brasileiro de Geografia e Estatística), FGV (Fundação Getúlio Vargas), INEP (Instituto Nacional de Estudos e Pesquisas) e Ibase (Instituto Brasileiro de Análises 


\section{RevistAleph}

Sociais e Econômicas). Além de consultas e diálogos diretos junto à população por meio de reuniões setoriais, audiência pública, visitas às escolas e uma pesquisa online.

Nesse sentido, essa pesquisa pode aprofundar o acesso a dados primários do município, bem como articular formas de diálogo direto, informações e análise da realidade local. Iniciando suas atividades, a comissão levantou uma diversidade de contatos do município, de forma a aprofundar e especificar cada diálogo em quatro setores: educacional, público, social e geração de trabalho e renda. Ao todo, foram levantadas mais de 119 organizações com atividades em Niterói, as quais foram convidadas para reuniões setoriais presenciais no campus. Tais reuniões seguiam uma dinâmica de apresentação do IFRJ e das atividades já desenvolvidas pelo campus e de escuta sobre diagnósticos e análise sobre a região, além das expectativas sobre ensino, pesquisa e extensão para o futuro campus do IFRJ em Niterói.

Figura 1: Foto de uma reunião setorial realizada no campus provisório no Caminho Niemeyer.

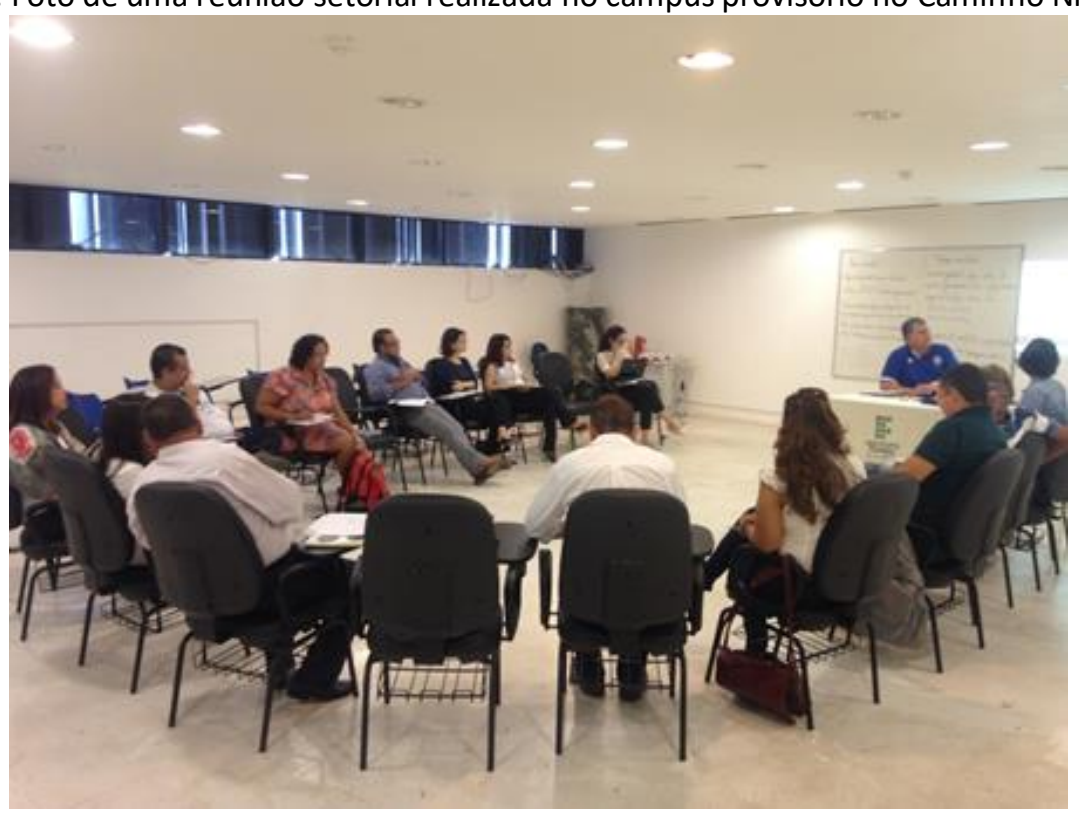

Fonte: Comissão PIC IFRJ - Niterói, 2017.

Apesar da baixa aderência dos convidados à agenda, visto que a menor parte dos convidados esteve presente, aqueles que participaram receberam positivamente a 


\section{RevistAleph}

iniciativa, com a expectativa de que momentos assim pudessem ter continuidade. As reuniões permitiram não apenas obter uma maior visibilidade do campus, mas explicitaram as tensões e características do município.

Foram destacadas preocupações para que o campus atendesse os jovens com maior vulnerabilidade social e exclusão no ensino médio, isso também frente às pressões do mercado de trabalho e do tráfico de drogas. Indicou-se um maior cuidado na inserção dessa população de baixa renda, negra, mulher e desempregada, com estímulo, como estrutura (como alimentação e transporte) e compreensão sobre esse público, aspectos que poderiam evitar a sua evasão. Também foi colocada a necessidade de atender o público de jovens e adultos e das comunidades tradicionais, além da indicação de diversos cursos dentro dos eixos de tecnologias, gestão e meio ambiente.

Durante a audiência pública realizada em 17/04/2017, na câmara municipal, um dos aspectos destacados foi justamente a necessidade da participação popular no processo de construção do campus, bem como a expectativa de transformação e melhoria para a região do Sapê, local do prédio definitivo do campus, bairro que apresenta uma forte desigualdade de renda e baixos índices de postos de trabalho e escolaridade da população.

Figura 2: Foto durante a audiência pública realizada. 


\section{RevistAleph}

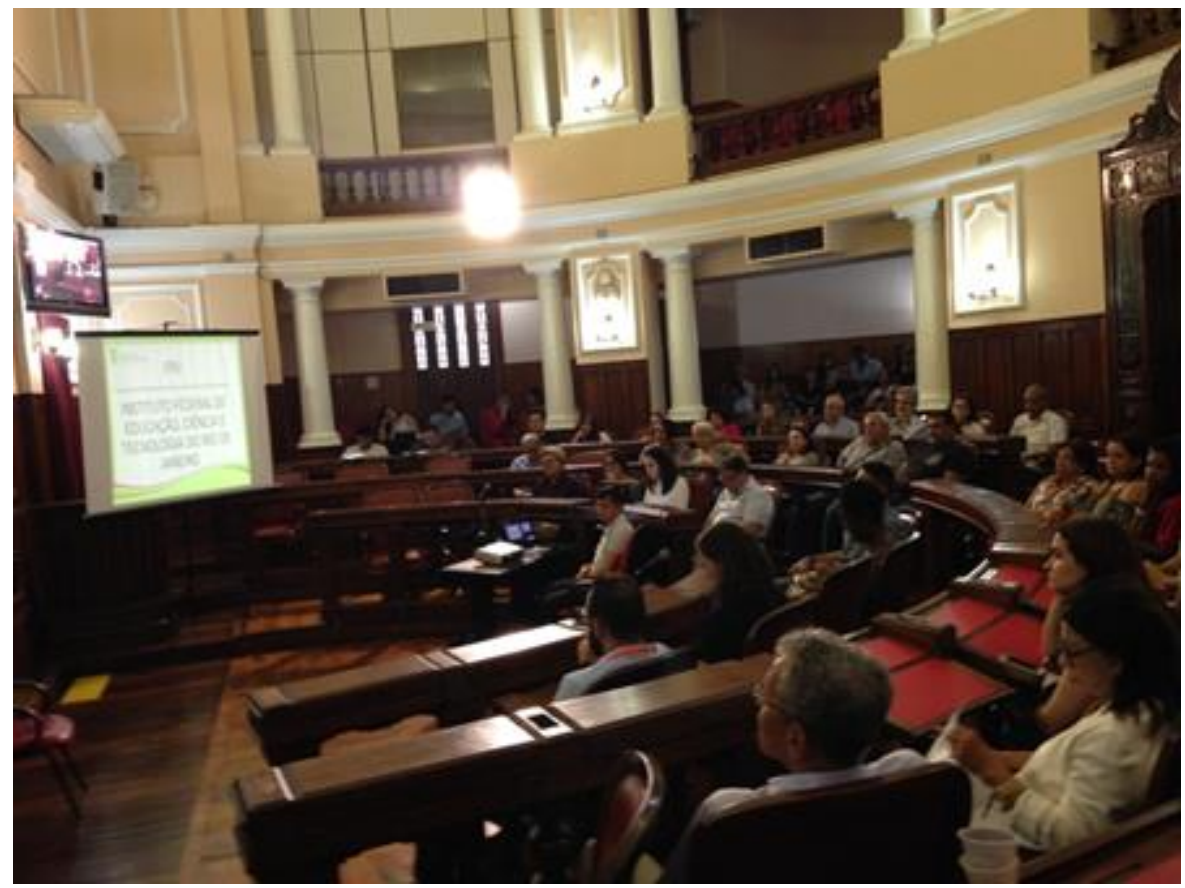

Fonte: Comissão PIC IFRJ - Niterói, 2017.

Já sobre a pesquisa quantitativa, esta foi realizada através de questionário aplicado em encontros presenciais com alunos do 9o ano e também online aberta a qualquer interessado do município ou fora dele. O resultado dessa iniciativa ampliou o mapeamento das principais expectativas e demandas educacionais na cidade de Niterói.

Nesse processo foi feita uma ampla divulgação da pesquisa online, em especial com apoio das redes sociais, obtendo-se a participação de 1.784 pessoas entre estudantes e membros da comunidade de Niterói, e 313 pessoas através de formulário impresso distribuído entre estudantes do nono ano em quatro escolas públicas locais.

Nesse levantamento obteve-se o perfil dos respondentes que, em resumo, tinham sua moradia concentrada em Niterói (62\%), São Gonçalo (22\%) e Rio de Janeiro (7\%), com renda entre 1 e 3 salários mínimos, e dos que trabalhavam atuavam, na sua maioria, na área administrativa.

Com relação aos resultados do total das respostas do levantamento quantitativo, online e presencial, obtivemos a preferência pelas áreas de informática e tecnologias (21,55\%), seguida pelas áreas ambiente e saúde (16,02\%), gestão e negócios 


\section{RevistAleph}

$(14,83 \%)$ e desenvolvimento educacional e social (12,54\%). Sobre os cursos indicados, cujas opções foram retiradas do Catálogo Nacional dos Cursos Técnicos, tiveram destaque: Administração (6,91\%), Programação de Jogos Digitais (5,96 \%) e, empatadas com 5,29\% cada, Informática para Internet e Meio Ambiente, seguidas por Análises Clínicas (4,43\%) e Tradução e Interpretação de Libras (4,01\%).

Tabela 1: Classificação das áreas escolhidas para o total de respondentes.

\begin{tabular}{|c|c|c|}
\hline Área & Número & Percentual \\
\hline Informática e Tecnologias & 452 & 21.55 \\
\hline Ambiente e Saúde & 336 & 16.02 \\
\hline Gestão e Negócios & 311 & 14.83 \\
\hline $\begin{array}{l}\text { Desenvolvimento Educacional e } \\
\text { Social }\end{array}$ & 263 & 12.54 \\
\hline Produção Cultural e Design & 227 & 10.82 \\
\hline Produção Alimentícia & 163 & 7.77 \\
\hline Turismo & 126 & 6.01 \\
\hline Controle e Processos Industriais & 120 & 5.72 \\
\hline Infraestrutura & 81 & 3.86 \\
\hline Não escolheram & 18 & 0.86 \\
\hline
\end{tabular}

Fonte: Comissão PIC IFRJ - Niterói, 2017. 


\section{RevistAleph}

Essa pesquisa corroborou os resultados das duas anteriores, destacando a preferência por cursos na área de administração. Mas vale destacar que em nenhuma das pesquisas quantitativas havia a opção aberta sobre a indicação de alguma área educacional, o que limitou as opções dos respondentes frente às alternativas disponíveis.

Analisando os demais dados fornecidos pela última pesquisa, percebe-se que o perfil do público que optou por cursos na área de Administração foi predominantemente feminino, estudante, com idade de até 34 anos. Já o interesse em Jogos Digitais foi majoritariamente masculino, juvenil e estudantil. Para o curso de Meio Ambiente, o público de interesse teve maior distribuição etária, entre estudantes e empregados, feminino e com maior distribuição junto aos municípios vizinhos, além de Niterói. A Informática para Internet também teve um público interessado mais equilibrado entre os sexos, jovem, estudante, tanto empregado como desempregado. Para Análises Clínicas destaca-se o perfil feminino, jovem e estudante. E por fim, Tradução e Interpretação de Libras também teve maior interesse feminino, maior distribuição entre as faixas etárias, público empregado e estudantil e com residência entre Niterói e São Gonçalo, assim como o curso de análises clínicas.

A indicação dos cursos mostra a diversidade dos respondentes e uma reiteração da construção social sobre os interesses por gênero, destacando-se algumas características gerais: enquanto o perfil com maior idade prefere os temas de meio ambiente e libras, o público mais jovem se destaca com a administração, áreas ligadas à informática e análises clínicas. Já com relação aos sexos, essa divisão também teve expressão: maior interesse feminino respectivamente em libras, análises clínicas, meio ambiente e administração, e interesse masculino, em especial os mais jovens do nono ano, em jogos digitais.

Um ponto importante dessa última pesquisa foi a ênfase destacada nas áreas de tecnologias, meio ambiente e gestão para a oferta de atividades no campus, que depois foi objeto de debate interno entre os servidores/as. Ressalta-se também que esta pesquisa teve diversas limitações, ainda que com uma amostra mais representativa e 


\section{RevistAleph}

heterogênea em comparação com as pesquisas até então realizadas: as perguntas eram fechadas, no sentido de permitir a escolha de apenas uma área e de um curso por respondente, dentre as opções que estavam disponíveis; a dificuldade dos próprios respondentes em preencher a pesquisa, e ainda, o pouco tempo em que a pesquisa esteve disponível para resposta e na sua própria divulgação.

Além disso, para o viés dado a esse artigo sobre participação, a consulta não correspondeu a uma continuidade de diálogo e participação na gestão escolar, visto que limitou-se a uma consulta específica e pontual. Nesse sentido, houve fragmentação do diálogo exercido, restrito ao momento em que eram necessárias fontes de informação para decisões que, depois, se dariam no ambiente interno da instituição, somente entre os seus servidores.

A tendência burocrática da escola, no sentido de seguir determinado procedimento e organização, não permitiu que a própria deliberação que se deu depois da consulta fosse também objeto de diálogo com o público externo, ou por alguma representação da comunidade consultada, sendo coordenada pela então direção do campus junto aos servidores. Isso porque também não havia até então no campus um espaço permanente para a participação da comunidade local, como o Cocam (Conselho do Campus), que apenas teve seu regulamento definido em 2020, ainda sem operacionalização.

Outra contradição na trajetória do campus é que nem todas as decisões seguintes sobre a oferta de cursos seguiram o rito de efetivar algum tipo de consulta e diálogo social que balizassem determinada escolha ou defesa, seja porque não havia condições ou interesse para tal, a exemplo da decisão sobre um curso de graduação. Isso mostra a complexidade de se estruturar um processo permanente de consulta e diálogo social que possa orientar continuamente a atuação de um Instituto Federal, requerendo a institucionalização de espaços de diálogo e a organização de seus processos e metodologias. 


\section{RevistAleph}

A despeito de toda a reiteração em torno da necessidade e obrigatoriedade da participação social no ambiente escolar, conforme trazido anteriormente, nas suas diversas instâncias e representatividades, há nítida distância entre a norma e a realidade. Mais do que um discurso, o processo participativo exige um compromisso moral que requer materialidade prática intensa, e por que não, também desgastante. 0 investimento em ouvir o outro demanda tempo, capacidade de articulação, comunicação e mediação de conflitos, percorrendo um caminho coletivo constante e interminável entre a escuta, a deliberação e a execução.

\section{Reflexões finais: o diálogo social como desafio permanente}

As consultas sociais empreendidas pelo campus Niterói permitiram, até determinado ponto, a escolha seguinte de cursos minimamente coerentes e balizados aos anseios sociais obtidos nos levantamentos realizados. A última consulta aprofundou aspectos sobre os respondentes e ampliou o acesso da população ao conhecimento e reconhecimento do IFRJ. Percebemos que o pertencimento social à instituição envolve necessariamente a participação da comunidade na sua elaboração e no seu cotidiano, conforme reforçado pelos autores pesquisados.

De outro lado, a experiência do IFRJ reflete os desafios históricos do país em estruturar e manter como permanentes processos democráticos e participativos, haja vista a história nacional desde o período colonial com regimes autoritários, como o Estado Novo e a ditadura militar, e nos processos recentes de impeachment de Dilma Rousseff (ou golpe jurídico-civil-midiático), na posterior eleição turbulenta (entremeada de fake news e polarização política) e nos assombros à democracia no governo atual (defesa do retorno ao regime militar e ataque a instituições, como o STF e o Congresso Nacional).

A experiência em análise mostra as margens de um diálogo e consulta social, que mesmo importantes e necessárias para a tomada de decisão institucional, além de 


\section{RevistAleph}

legalmente uma exigência e uma necessidade para a construção efetiva de uma instituição educacional, foram limitadas. Isso em especial quando não há um espaço permanente de participação que possa se atualizar e manter a interação com a sociedade.

Esse tema também explicita a complexidade dos processos de participação que envolvem relações de poder, mediações e acesso à informação e compreensão por parte daqueles que são ou serão participantes. Invariavelmente, a abertura aos processos democráticos envolve conflitos e pontos de vista distintos, na tensão entre liberdade e autoridade (FREIRE e SHOR, 1987), cuja mediação se faz necessária para organizar o seu processo.

Frente à insistência da defesa e do uso da meritocracia na sociedade, justificada nos mais variados termos, inclusive pelas práticas educativas tradicionais, o que confere legitimação às desigualdades existentes, ainda se faz necessário lutar por uma escola democrática que promova valores como solidariedade, cooperação, justiça e trabalho, de forma que a educação possa servir à humanidade e harmonizar interesses individuais e coletivos, retomando os termos do Manifesto dos Pioneiros da Educação Nova (1932).

Conforme colocado por Motta (1984) a participação pode alcançar uma profundidade no âmbito institucional e pedagógico, dentro e fora das salas de aula, tendo como premissa um processo contínuo de escuta e diálogo, que promove uma formação com autonomia e responsabilidade. E que, como coloca Freire e Shor (1987), num diálogo que não seja apenas recurso técnico e utilitarista para tomada de decisões, mas naquilo que nos constitui como humanos e na construção de uma sociedade justa e democrática. 


\section{RevistAleph}

\section{Referências}

ANTUNES, Ricardo. Adeus ao trabalho? Ensaio sobre as metamorfoses e a centralidade do mundo do trabalho. 16. Ed. São Paulo: Cortez, 2015.

BRASIL. Ministério da Educação. Diretrizes Curriculares Nacionais Gerais da Educação Básica / Ministério da Educação. Secretaria de Educação Básica. Diretoria de Currículos e Educação Integral. Brasília: MEC, SEB, DICEI, 2013.

FREIRE, Paulo; SHOR, Ira. Medo e ousadia: o cotidiano do professor. 3. ed. Rio de Janeiro: Paz e Terra, 1987.

IFRJ, Campus Niterói. Plano de Implementação do Campus Niterói (PIC). Realizada pela Comissão de Pesquisa do Perfil da Cidade de Niterói para criação dos Cursos do Campus, junho de 2017.

MOTTA, Prestes. Fernando. Administração e Participação: reflexões para a educação. Revista de Educação da Faculdade de Educação. São Paulo: USP, v. 10, n. 2, p. 199-207, 1984.

O MANIFESTO DOS PIONEIROS DA EDUCAÇÃO NOVA (1932). In: Revista HISTEDBR On-line, Campinas, n. especial, p.188 -- 204, ago. 2006. Disponível em:

http://www.histedbr.fe.unicamp.br/revista/edicoes/22e/doc1_22e.pdf. Acesso em 29/05/2018.

SAVIANI, Dermeval. História da história da educação no Brasil: um balanço prévio e necessário. Revista Científica. São Paulo, Universidade Nove de Julho, vol. 10, núm. Esp, pp. 147-167, julho, 2008.

TEDESCO, Carlos. Juan. O novo pacto educativo: educação, competitividade e cidadania na sociedade moderna. São Paulo: Editora Ática. 2001.

Data do envio: $23 / 07 / 2020$

Data do aceite: $04 / 11 / 2020$ 